men. The disease which is thus stigmatized and fined is not a partial one. The good, the brave, the young, the beautiful, the old, the dastardly, and the base, are alike its victims.

Regumque turres."

$$
\text { " ‘quo pulsat pede, pauperum tabernas }
$$

Neither the genius of a Southey nor a Tasso, not the wit and vigour of a Swift, not the tenderncss of a Cowley, nor the piety and talent of a Cruden or a Hall, nor the genial humour and kind-heartedness of a Lamb, can exempt us from its influence. Let, then, such anomalies be removed from our laws and institutions. Let us be wise and just, acting in perfect harmony with the laws of science and the dictates of religion. Let us rise superior to the ignorance and follies of the middle ages, and regard all diseases and their consequences in a like spirit; or if making any difference, bestowing our sympathies with the greatest intensity on that unhappy being who, while suffering from the pangs of the body, is harassed by the troubles of the mind, and who, by his very helplessness, appeals alike to the justice and to the charity of our common nature.

\section{ON A CASE OF RETENTION OF URINE.}

\section{Bx W. M. FAIRBRoTHER, Esq., Surgeon, London.}

A REMARKable case of retention of urine came under my notice last week. The patient, a female about thirty years old, who had been under the care of a practitioner in her neighbourhood for one week, when seen by me was suffering from irritative fever, while an immense tumour, extending from the pubes to the navel, occupied nearly two-thirds of the abdomen, and presented, on percussion, the ordinary sign of fluid in a cavity. The female catheter had been introduced, by the gentleman in attendance, two days previously, some urine was drawn off, when it suddenly stopped. It was again introduced during my visit, and no urine flowing, I considered that the distended bladder had drawn up the neck of that viscus from its natural situation, and elongated the meatus. I then had recourse to an ordinary gum-elastic male catheter without the stilette, and nearly seven imperial pints of urine were drawn off.

I mention this case, to remark what extraordinary powers of endurance were manifested here, that a rupture of the bladder should not have taken place.

London-road, August 7 th, 1848.

\section{ON THE}

EFEECTS OF SEA-BATHING AND CLIMATE ON THE HUMAN CONSTITUTION.

By Thomas HUNT, M.R.C.S. Eng., Herne Bay. (Continued from p. 287, vol. ii. 1847.)

The Salutary Agents of the Coast.

To the agents more obviously promotive of health to the seaside visitor-viz., the sea, the sea air, and medical treatmentmay probably be added some peculiarities in the electro-magnetic currents, of which too little is as yet known to enable us to speak with certairity.

The sea air is probably the most important of these salutary agents. The rapidity with which a patient recovers from chronic disease depends, cateris paribus, upon the number of hours per diem during which he breathes the pure open air. If two hours in the twenty-four will restore a patient in four months, then four hours in the same period will restore the same patient in two months, and eight hours in one month. Eight hours, on an average, should be spent in the open air daily, in order that a patient may have the full benefit of the sea air; and this is no extravagant proposition, it is but the third part of the whole time spent at the sea-side. And yet, how many patients, taking half an hour's walk every fine day, and sitting for an hour or two with their chamber windows open facing the sea, suppose, in all simplicity, that they are trying the sea air. The great secret of treating disease successfully at the sea-side (scrofula especially) consists in the multiplication of contrivances calculated to keep the patient out of doors all the day long. And this is the most difficult point to accomplish that can well be imagined. It requires stratagems and schemes, and perseverance and vigilance, all of which are frequently ineffectual. Patients will submit to be drugged, and dieted, and blistered, and tortured to almost any extent, but cannot be persuaded to inhale the balmy air of heaven. One patient is weak, and cannot walk; another is "nervous," and cannot ride; a third is giddy-headed, and cannot bear a row or a sail; a fourth has a fair complexion or weak eyes, and cannot endure the rays of the sun; a fifth has weak lungs, and is afraid of the wind; a sixth is apprehensive that it may rain; a seventh fancies that the wind is easterly when it is blowing due west; and the rest are afraid of the cold or the heat, the damp or the dust. The health of patients visiting the coast depends more upon the success with which we are enabled to combat these prepossessions than upon the most skilful use of the materia medica. It is not beneath the dignity of a medical man to promote and encourage amusements in the open air. Such a locality as this, for instance, presents many facilities of this kind, among which may be mentioned a pier, stretching in a straight line more than half a mile over the sea, traversed frequently by a sailing car, with accommodation for passengers; a green slope where scores of children may roll and romp " from morn to dewy eve;" rustic seats for invalids who like to watch their gambols; a cricket. ground, opportunities for the practice of skittles, archery, kite-flying, botanizing, geologizing, pic-nicking, hay-making, nutting, blackberrying, or hop-gathering, each in its respective season, and a good supply of horses, donkeys, carriages, \&c. Much is also gained for the invalid by encouraging broadbrimmed straw hats, blue veils and spectacles, high dresses, dishabille habits, early hours, and everything which is rational, natural, and un-fashionable; the sole end and aim of all being to evacuate the lodgings from morning till sunset. On the contrary, rides in close carriages, fashionable promenades at eventide, evening soirees and concerts, midnight dancing in hot, crowded, fetid rooms, theatrical exhibitions-all these, the usual elements of fashionable watering-places, are great hindrances to recovery. IJalf of the chronic disenses to which the English population is exposed, either result from, or are aggravated by, the artificial habits of civilized life; and half the secret of their cure consists in a return to nature. If the dissipated mind has retained in the midst of its distractions any portion of that love of the beauties of nature which is innate in all of us, - for " the young mind is always delighted with rural scenery,"-it is impossible to calculate the amount of therapeutical efficacy which such a patient may find in the simple delights of the country, and the exhaustless variety of Nature's rural beauties which abound in the neighbourhood, not of Brighton or of Ramsgate, but of less frequented watering-places.

Medical Treatment. - It occasionally happens that the bracing influences of the coast, independently of medicine and management, will suffice for the restoration of a patient, and the removal of chronic disease which has long resisted the most judicious administration of drugs in some distant atmosphere of smoke. This has happened even under a reckless use of sea-bathing, and it has occurred when the patient has not bathed at all, but simply changed his residence and his habits for a time. Yet of those who thus try the sea-side as a remedy for disease, by far the majority find themselves, at the end of the month's trial, worse rather than better. The stimulus of the first few days' change having passed off, the system gets into a condition unfavourable to recovery, without proper care and management. Many such patients being disappointed in their expectations, return home, and, hopeless of relief from " the faculty," become the victims of the quack. We may exhaust our eloquence, and weary our legislators with remonstrances for the more effectual putting down of quackery; but the most natural and effectual check to the prevalence of this enormous fraud will be found in the advancement of science and the improvement of medical ethics. A drowning man will catch at straws, and patients will speculate in quackery when the regular practitioner can do nothing for their relief. In a vast proportion of the cases of chronie disease which are thus abandoned to the murderer, I am persuaded the patient might be restored by the means which we already have in our hands. But there must be a better management of our appliances, particularly of the therapeutica littorosa.

Of the chronic diseases which are curable in the present state of our art, some will yield to medical treatment alone, the patient remaining at home; others will yield to sea-side influences alone, without guidance or medicine; but there is a large proportion which will not yield without both of these combined; and these are the cases on which the quack fattens. It is in the power of the profession to prevent this discrace. At every watering-place in England, both marine and inland, there are to be found medical practitioners who have won the esteem of the profession. These men must know, from their position, and the experience it affords them, the best method of securing to a patient the peculiar advat- 